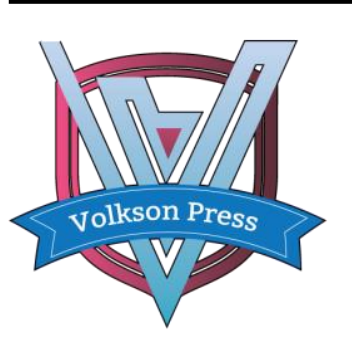

\title{
INVESTIGATION ON THAT FEASIBILITY OF A TAX-DEFERRED ENDOWMENT INSURANCE IN GUIZHOU PROVINCE
}

\author{
Shaodong Ma, XiongBo Ruan \\ School of Finance, Guizhou University of Finance and Economics, Guiyang, Guizhou, China
}

This is an open access article distributed under the Creative Commons Attribution License, which permits unrestricted use, distribution, and reproduction in any medium, provided the original work is properly cited.

\section{ARTICLE DETAILS}

\section{Article History:}

Received 26 June 2018 Accepted 2 July 2018

Available online 1 August 2018

\begin{abstract}
Through the establishment of the individual tax deferred pension replacement rate model and tax expenditure model to calculate the relevant data of Guizhou province. The pilot notice is not feasible in Guizhou province. The replacement rate of the pension insurance is directly related to the age of the policyholder, the salary, and the male replacement rate is greater than the female; If the tax rate at the time of the pension is greater than the rate at which the insured is, the government's tax expenditure is negative, which is not good for the residents to get the incentive to buy a tax deferred pension. To raise the salaries of residents, to increase the awareness of the residents, to make reasonable tax rates and to draw on the advice of the international experience design system.
\end{abstract}

\section{KEYWORDS}

Individual tax deferred pension insurance, EET model, replacement rate model.

\section{INTRODUCTION}

Modern society perfect endowment insurance system basically has: social basic endowment insurance, enterprise annuity and commercial endowment insurance. The problem of China's pension insurance is the unbalanced development of the three pillars. The problem with our country's pension insurance is that the three pillars are uneven, and the individual tax deferred pension insurance (ITDPI) is an effective measure of the problem. ITDPI is the personal tax deferred pension insurance is a government that encourages individuals to buy their business pension insurance, and, in a certain amount, when they pay for their business pension insurance, they allow individuals to deduct the premiums from their pre-taxes, and then they pay their personal taxes on their retirement benefits, and then they pay their personal taxes on the pension. The time periods when the individual's tax-deferred pension insurance is Taxed and untaxed can be divided into three models: EET, ETE and ETT.

\section{LITERATURE REVIEW ON INDIVIDUAL TAX DEFERRED PENSION INSURANCE}

Use tax incentives to encourage the development of commercial endowment insurance is the common practices of international society. A study of the data analysis of the American IRAs account and found a significant correlation between the marginal tax rate and the IRAs [1]. A researcher believed that tax incentives would increase the wealth of residents [2]. Another researcher argues that preferential tax deferred can promote the development of endowment insurance [3]. Domestic research on ITDPI mainly includes the following categories: (1) the analysis and summary of foreign relevant practical experience are combined with domestic practice, and the development strategy of individual tax deferred pension insurance in China is proposed. It's been suggested, mainly with a various researcher. (2) the implementation of ITDPI in specific regions was studied [4-6]. (3) based on the measurement of data implementation using relevant models, countermeasures and Suggestions for implementing individual tax deferred endowment insurance are obtained [7-9]. At present, most of literature are theoretical studies to analyze the possible effects of ITDPI. In this paper, based on the pilot scheme, using models to measure Guizhou province, which provides Suggestions and Suggestions for the implementation of the tax deferred endowment insurance of the individual.

\section{ESTABLISHMENT OF INDIVIDUAL TAX DEFERRED PENSION MODEL}

\subsection{Government fiscal and tax expenditure model}

Assuming that the applicant purchases endowment insurance at the age of $\mathrm{k}$, retires at the age of $\mathrm{n}$, the investment rate of endowment insurance funds is $r$, the tax rate at the purchase stage is $T_{0}$, and the tax rate at the receiving stage is $T_{1}$, then the model of fiscal tax expenditure of unit premium government under EET mode and TEE mode can be set as:

$$
\begin{aligned}
& \mathrm{V}_{n(T E E)}=\left(1-T_{0}\right)(1+r)^{n-k} \\
& \mathrm{~V}_{n(E E T)}=0.75 *\left(1-T_{1}\right)(1+r)^{n-k}+0.25 *(1+r)^{n-k} \\
& V_{n(E E E)}=(1+r)^{n-k}
\end{aligned}
$$

Among them, Vn (EEE) can be understood as the accumulation value of unit premium at time $\mathrm{K}$ under the effect of investment return $\mathrm{r}$ at time $\mathrm{n}$. Since the role of the tax led to (3) and (1), (2) type appeared difference, both for the TEE mode and EET mode of tax preferences. In other words, it is the government tax expense, discounted the above tax expenditure to the present value of time $\mathrm{K}$, and $\mathrm{R}$ represents interest rate, and its expression is:

$$
\begin{aligned}
& T_{T E E}=\frac{V_{n(E E E)}-V_{n(T E E)}}{(1+R)^{n-k}}=\frac{\left\{(\mathbf{1}+\mathbf{r})^{n-k}-\left(1-T_{0}\right)(1+r)^{n-k}\right\}}{(1+R)^{n-k}} \\
& T_{E E T}=\frac{V_{n E E E}-V_{n E E T}}{(1+R)^{n-k}}=\frac{\left\{(1+r)^{n-k}-0.75 *\left(1-T_{1}\right)(1+r)^{n-k}-0.25 *(1+r)^{n-k}\right\}}{(1+R)^{n-k}}
\end{aligned}
$$

Since the wage is not always the same, it assumes that the annual growth rate of "A", the annual rate of premium, is going to be paid once A year, and then it goes from " $K$ " to " $n$ " in " $n$ " time, and the present value of the "EET" model is the present value of the tax expenditures of the TEE model:

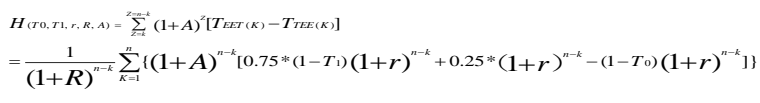

\subsection{Individual tax deferred pension replacement rate model}

(1) Premium cumulative value based on whether or not the salary rises can be divided into the fixed premium accumulative value and the cumulative value of the earned premium, and the salary is expressed as W, 
in which the accumulated value of fixed premium can be expressed as:

$f(n-k)=q \cdot W \frac{(1+r)^{n-k}-1}{r}$

Premium wages proportion cumulative values can be represented as:

$f_{(n-k)}=q \cdot W \frac{(1+r)^{n-k}+(1+A)^{n-k}}{r-A}(\mathrm{r} \neq \mathrm{A})$,

If $\mathrm{r}=\mathrm{A}, f_{(n-k)}=q \cdot W(n-k)(1+r)^{n-k-1}, \mathrm{q}$ represents the

payment ratio.

(2) Annual pension benefits. According to the actuarial equivalence principle, the annual pension benefits of the insured can be calculated as:
$\boldsymbol{L}_{(n-k)}=\frac{f_{(n-k)}}{a_{\ddot{x}}}$, and $\quad \ddot{a} x=\sum_{m=0}^{m-n}(1+r)^{m}{ }_{. t} P_{n}{ }^{\mathrm{x}}$ is the retirement age, ${ }^{t} P_{x}$ is the probability that $\mathrm{x}$ year old people will live for $\mathrm{t}$ years.

\section{INDIVIDUAL TAX DEFERRED IMPLEMENTATION EFFECT MEASUREMENT}

\subsection{Variable selection and hypothesis}

According to the data of Guizhou province and relevant departments in 2016, the variable hypothesis of this paper is as follows (see table 2)

Table 2: Variable selection and hypothesis

\begin{tabular}{|l|l|l|l|}
\hline variable name & & & \\
\hline wage growth rate & $6 \%$ & $8 \%$ & \\
\hline pension investment rate & $4 \%$ & $5 \%$ & $7 \%$ \\
\hline amount of payment & 3690 Yuan per year & & \\
\hline tax rate in the premium phase & $3 \%$ & & \\
\hline retirement age & Men retire at 60 & women at 55 & \\
\hline age of insurance & 30 years old & 40 years old & 50 years old \\
\hline tax rate at the pension stage & $2 \%$ & $3 \%$ & $10 \%$ \\
\hline
\end{tabular}

Notes: Assume that the insured continues to pay premiums from the date of insurance until retirement.

\subsection{Calculation results}

\subsubsection{Tax expenditure}

By table 4 ,When $\boldsymbol{T}_{\mathrm{o}}$ equal to $\boldsymbol{T}_{\boldsymbol{1}}$, the present value of government tax expenditures is zero; $\boldsymbol{T}_{\mathbf{1}}<\boldsymbol{T}_{\mathrm{o}}$ the present value of government tax expenditure is positive, Whereas negative, there is no government tax expenditure; The return rate and interest rate of pension fund are positively correlated with the absolute value of the present value of government tax expenditure. Under the same conditions, the present value of government tax expenditures generated by male insurance is greater than that of female insurance. Insured moments earlier, government tax expenditure caused by the greater the present value. (see table 3)

Table 3: Government tax expenditure

\begin{tabular}{|c|c|c|c|c|c|c|c|c|}
\hline \multirow{2}{*}{ RRI（r) } & \multirow{2}{*}{ IR（R） } & \multirow{2}{*}{ TRRP } & \multicolumn{2}{|c|}{30 years old } & \multicolumn{2}{|c|}{40 years old } & \multicolumn{2}{|c|}{50 years old } \\
\hline & & & male & female & male & female & male & female \\
\hline \multirow{6}{*}{$4 \%$} & \multirow{3}{*}{$2.5 \%$} & $2 \%$ & 1652 & 1388 & 1123 & 854 & 579 & 296 \\
\hline & & $4 \%$ & 0 & 0 & 0 & 0 & 0 & 0 \\
\hline & & $10 \%$ & -4955 & -4163 & -3368 & -2562 & -1738 & -887 \\
\hline & \multirow{3}{*}{$4 \%$} & $2 \%$ & 1068 & 965 & 840 & 687 & 501 & 275 \\
\hline & & $4 \%$ & 0 & 0 & 0 & 0 & 0 & 0 \\
\hline & & $10 \%$ & -3205 & -2895 & -2519 & -2061 & -1503 & -825 \\
\hline \multirow{6}{*}{$5 \%$} & \multirow{3}{*}{$2.5 \%$} & $2 \%$ & 1976 & 1606 & 1259 & 929 & 613 & 305 \\
\hline & & $4 \%$ & 0 & 0 & 0 & 0 & 0 & 0 \\
\hline & & $10 \%$ & -5927 & -4817 & -3776 & -2788 & -1839 & -914 \\
\hline & \multirow{3}{*}{$5 \%$} & $2 \%$ & 956 & 879 & 777 & 648 & 482 & 270 \\
\hline & & $4 \%$ & 0 & 0 & 0 & 0 & 0 & 0 \\
\hline & & $10 \%$ & -2876 & -2637 & -2331 & -1942 & -1445 & -810 \\
\hline \multirow{6}{*}{$7 \%$} & \multirow{3}{*}{$2.5 \%$} & $2 \%$ & 2862 & 2168 & 1590 & 1103 & 686 & 323 \\
\hline & & $4 \%$ & 0 & 0 & 0 & 0 & 0 & 0 \\
\hline & & $10 \%$ & -8587 & -6505 & -4770 & -3308 & -2058 & -969 \\
\hline & \multirow{3}{*}{$7 \%$} & $2 \%$ & 789 & 741 & 673 & 579 & 446 & 261 \\
\hline & & $4 \%$ & 0 & 0 & 0 & 0 & 0 & 0 \\
\hline & & $10 \%$ & -2366 & -2222 & -2020 & -1737 & -1339 & -782 \\
\hline
\end{tabular}

Notes: Rate of return on investment(RRI),interest rate(IR),Tax rate of receiving period(TRRP).

\subsubsection{Annuity Pension and the replacement ratio}

By table 4, the accumulative value of the premium is negatively correlated with the age of insurance, which is that the earlier the age, the higher the premiums are; The age difference between the sexes, and therefore, under the same age, the male insurance premiums are more than the female; Wage growth rate less than the replacement rate of return on investment and wage growth rate is greater than the return on investment, compared to the replacement rate of the former than the latter.(see chart 4). 
Topics In Education, Culture and Social Development (TECSD) 1(1) (2018) 40-42

Table 4: Substitution effect of endowment insurance

\begin{tabular}{|c|c|c|c|c|c|c|c|c|}
\hline & \multirow{2}{*}{ RRI } & & \multicolumn{2}{|c|}{30 years old } & \multicolumn{2}{|c|}{40 years old } & \multicolumn{2}{|c|}{50 years old } \\
\hline & & & male & female & male & female & male & female \\
\hline & \multirow{2}{*}{$4 \%$} & CVP & 222096 & 164918 & 117921 & 79293 & 47544 & 21448 \\
\hline & & ACA & 23694 & 14036 & 12581 & 6748 & 5072 & 1825 \\
\hline & \multirow{2}{*}{$5 \%$} & CVP & 263097 & 188999 & 130941 & 85451 & 49808 & 21881 \\
\hline & & $\overline{\mathrm{ACA}}$ & 31200 & 18023 & 15528 & 8149 & 5906 & 2087 \\
\hline & \multirow{2}{*}{$7 \%$} & CVP & 374065 & 250466 & 162342 & 99511 & 54713 & 22723 \\
\hline & & ACA & 53555 & 40799 & 23242 & 16210 & 7833 & 3701 \\
\hline \multirow{3}{*}{ WGR is $6 \%$} & $4 \%$ & S (\%) & 7.1 & 5.6 & 6.7 & 4.8 & 4.8 & 2.3 \\
\hline & $5 \%$ & S (\%) & 9.3 & 7.2 & 8.3 & 5.8 & 5.6 & 2.6 \\
\hline & $7 \%$ & S (\%) & 16 & 16.3 & 12.4 & 11.6 & 7.5 & 4.7 \\
\hline \multirow{3}{*}{ WGR is $8 \%$} & $\underline{4} \%$ & S (\%) & 4 & 3.5 & 4.6 & 3.6 & 4 & 2.1 \\
\hline & $\underline{5 \%}$ & S (\%) & 5.3 & 4.5 & 5.7 & 4.4 & 4.7 & 2.4 \\
\hline & $7 \%$ & S (\%) & 9.1 & 10.2 & 8.5 & 8.8 & 6.2 & 4.3 \\
\hline
\end{tabular}

Notes: Cumulative value of premium (CVP), Annual collar allowance (ACA), substitution rate (S), wage growth rate (WGR)

\section{CONCLUSIONS}

Through the above replacement model and government tax expenditure model combined with the actual measured results in Guizhou, in this paper, the development of Guizhou province tax deferred type endowment insurance puts forward the following Suggestions: (1) formulate reasonable employment policies and wage growth policies and improve the income of residents. The calculation finds that the pension replacement rate in Guizhou province is too low, and the government should encourage the employees to improve the salary level by learning, skill training and other methods, so as to enhance the purchasing power of residents and increase the replacement rate of pension in personal accounts. (2) the replacement rate of endowment insurance and pension investment yields, insurance is closely related, endowment insurance through propaganda, improve resident's endowment insurance consciousness, encouraging people to buy endowment insurance as soon as possible, to ensure that the standard of living after retirement. (3) take a look at the experience of the American "401K" and the German "REZT reform", to promote the development of a tax deferred retirement insurance policy. (4) By adjusting the tax rate of the period $\left(T_{1}\right)$, which is below, equal or slightly higher than the current rate $\left(T_{0}\right)$, increase the rate of incentive for the residents to purchase a tax-deferred pension insurance and the replacement rate of the pension insurance, to ensure the implementation of the individual tax deferred pension insurance.

\section{REFERENCES}

[1] 0 'neil, C.J., Thompson, G.R. 1987. Participation in IRAs: An Empirical Investigation. National Tax Journal, 40 (4).
[2] Gomes, F., Michaelides, A. 2005. Optimal life-cycle Asset Allocation: Understanding the Empirical Evidence. The Journal of Finance,60 (2).

[3] Banterle, C.B. 2002. Incentives to contribute to Supplementary Pension Funds: Going Beyond Tax Incentives. Risk and Management, 27 (4)

[4] Zhang, Y.W., Wang, G.J. 2018. Implications of the Factors Influencing the Individual Income Tax Deferred Pension Insurance in the United States on China. Wuhan finance, (1), 69-75.

[5] Wu, X.Y., Xu, L. 2014. Welfare Effect of Individual Tax Deferred Endowment Insurance. Research on financial and economic issues, (10), 85-90.

[6] Wu, X.Y. 2014. Regressive Effect of Individual Income Tax Deferred Pension Insurance and its Overcoming. Tax and economy, (1), 1-7.

[7] Wang, L. 2014. Research on Tax Effect of Tax Deferred Endowment Insurance. Financial Teaching and Research, (6), 77-79.

[8] Liu, X.L., Zhang, J.W. 2016. Research on Implementation Conditions of Individual Tax Deferred Pension Insurance, Taking Fujian Province as an Example. Time finance, (20), 215-217.

[9] Liu, M.J. 2016. Measurement and Consideration of Policy Variables of Individual Tax Deferred Endowment Insurance System, Empirical Measurement Based on Shanghai Social and Economic Data. Tax and Economy, (3), 68-75. 